\title{
Phenotypic and genotypic characterization of Staphylococci causing breast peri-implant infections in oncologic patients
}

\author{
Ramona Barbieri ${ }^{1}$, Marianna Pesce ${ }^{2}$, Simonetta Franchelli ${ }^{3}$, llaria Baldelli ${ }^{2}$, Andrea De Maria ${ }^{4}$ and Anna Marchese ${ }^{5^{*}}$
}

\begin{abstract}
Background: Staphylococcus epidermidis and S. aureus have been identified as the most common bacteria responsible for sub-clinical and overt breast implant infections and their ability to form biofilm on the implant as been reported as the essential factor in the development of this type of infections. Biofilm formation is a complex process with the participation of several distinct molecules, whose relative importance in different clinical settings has not yet been fully elucidated. To our knowledge this is the first study aimed at characterizing isolates causing breast peri-implant infections.
\end{abstract}

Results: Thirteen S. aureus and seven S. epidermidis causing breast peri-implant infections were studied. Using the broth microdilution method and the E-test, the majority of the strains were susceptible to all antibiotics tested. Methicillin resistance was detected in two S. epidermidis. All strains had different RAPD profiles and were able to produce biofilms in microtitre plate assays but, while all $S$. aureus carried and were able to express icaA and icaD genes, this was only true for one S. epidermidis. Biofilm development was glucose- and NaCl-induced ( $5 \mathrm{~S}$. aureus and $1 \mathrm{~S}$. epidermidis) or glucose-induced (the remaining strains). Proteinase $\mathrm{K}$ and sodium metaperiodate treatment had different effects on biofilms dispersion revealing that the strains studied were able to produce chemically different types of extracellular matrix mediating biofilm formation.

All S. aureus strains harboured and expressed the atIA, CIFA, FnA, eno and cna genes and the majority also carried and expressed the sas $G(10 / 13)$, ebpS (10/13) genes.

All S. epidermidis strains harboured and expressed the atIE, aae, embp genes, and the majority (six strains) also carried and expressed the fbe, aap genes.

Genes for S. aureus capsular types 5 and 8 were almost equally distributed. The only leukotoxin genes detected were lukE/lukD (6/13).

Conclusions: S. aureus and S. epidermidis breast peri-implant infections are caused by heterogeneous strains with different biofilm development mechanisms.

Since the collagen adhesin (cna) gene is not ubiquitously distributed among $S$. aureus, this protein could have an important role in the cause of breast peri-implant infections.

Keywords: Implant infections, Biofilm, Staphylococcal infections, ica gene, biofilm-related genes, MSCRAMMs

\footnotetext{
* Correspondence: anna.marchese@unige.it

${ }^{5}$ IRCCS-AOU San Martino IST, Microbiology Unit DISC, University of Genoa,

Largo Rosanna Benzi 10, 16132 Genoa, Italy

Full list of author information is available at the end of the article
} 


\section{Background}

Immediate breast reconstruction, using tissue expanders and implants, has become a standard of care for almost all women requiring mastectomy for breast cancer [1-3]. However, after implantation, patients may experience local complications during the ensuing years, with peri-implant infection being one of the most common problems, with an infection rate ranging from 0 to 29 percent [4].

The most traditional approach to severe or refractory breast periprosthetic infection remains removal of the device. However, removal makes subsequent reinsertion and re-expansion more difficult, since the soft tissue retracts rapidly to close the expanded pocket [5].

The majority of cases reported identify Staphylococcus epidermidis and $S$. aureus as the most common bacteria responsible for sub-clinical and overt breast implant infections.

Bacteria may reach the implants during or after placement and their ability to form biofilms on the implant has been reported as the essential factor in the development and persistence of infection. Biofilm formation is a complex process with the participation of several distinct molecules, whose relative importance in different clinical settings has not yet been fully elucidated.

Specific staphylococcal surface proteins impacting adhesion to abiotic surfaces (AtlA, AtlE, Bap/Bhp) as well as a vast array of proteins called MSCRAMMs (Microbial Surface Components Recognizing Adhesive Matrix Molecules) promoting colonization of medical implants have been identified [6]. In S. aureus and S. epidermidis, production of an extracellular polysaccharide promoting intercellular adhesion (PIA), also called polymeric $\mathrm{N}$-acetyl-glucosamine (PNAG) is currently the bestcharacterised biofilm mechanism [7]. PIA/PNAG is synthesised by enzymes encoded by the ica operon.

Once this operon is activated, four proteins are transcribed icaA, ica $\mathrm{D}$, icaB and icaC. The expression of icaA alone induces low enzymatic activity, however, the simultaneous expression of ica $\mathrm{A}$ and icaD promotes a significant increase in the amount of polysaccharide [8].

However, recent studies have begun to highlight the existence of PIA/PNAG-independent biofilm mechanisms in both species [9]. Accumulation-associated protein (Aap) independently or toghether with ica operon, has also been suggested to be important in coagulase-negative staphylococci [10]. In S. aureus and S. epidermidis more additional surface proteins such as SasG, extracellular matrix binding protein (Embp), biofilm-associated protein (Bap) and the fibronectin-binding proteins FnbpA and B, were implicated in matrix formation. These findings suggest that other surface proteins may also be involved in biofilm development. In some strains, biofilm formation may be mediated additionally or exclusively by specific surface proteins (Bap/Bhp and Aap) [6].
While several studies have extensively described the distribution of genes involved in biofilm formation and virulence in Staphylococcal strains causing orthopaedic peri-implant infections, to our knowledge, this is the first study characterizing isolates causing breast periimplant infections.

\section{Results}

Antimicrobial susceptibility and mecA presence

All S. aureus isolates were susceptible to, oxacillin, cotrimoxazole, daptomycin, gentamicin, linezolid, rifampin, tetracycline and vancomycin. Ciprofloxacin- and erythromycin resistance was detected in one $(1 / 13,7.7 \%)$ and three $(3 / 13,23.1 \%)$ strains, respectively (Table 1$)$. Two out of the three erythromycin-resistant $S$. aureus showed inducible clindamycin resistance.

All S. epidermidis were susceptible to, ciprofloxacin, clindamycin, daptomycin, linezolid, rifampin, tetracycline and vancomycin. Oxacillin, erythromycin, gentamicin and co-trimoxazole resistance was detected in $2 / 7$, $5 / 7,2 / 7$ and $1 / 7$ strains, respectively.

Table 1 Susceptibility of 20 Staphylococci isolated from breast implant infections

\begin{tabular}{|c|c|c|c|c|c|}
\hline & & Range & MIC50 & MIC90 & $\% \mathrm{~S}$ \\
\hline \multirow[t]{11}{*}{ S. aureus (13) } & ciprofloxacin & $\leq 0.12-4$ & $\leq 0.12$ & 1 & 92.3 \\
\hline & cotrimoxazole & $\leq 2 / 38$ & $\leq 2 / 38$ & $\leq 2 / 38$ & 100 \\
\hline & clindamycin & $\leq 0.25$ & $\leq 0.25$ & $\leq 0.25$ & $100^{*}$ \\
\hline & erythromycin & $\leq 0.25-\geq 8$ & $\leq 0.25$ & $\geq 8$ & 76.9 \\
\hline & tetracycline & $\leq 1$ & $\leq 1$ & $\leq 1$ & 100 \\
\hline & rifampicin & $\leq 0.5$ & $\leq 0.5$ & $\leq 0.5$ & 100 \\
\hline & linezolid & 1 & 1 & 1 & 100 \\
\hline & vancomycin & $\leq 0.5-1$ & 1 & 1 & 100 \\
\hline & oxacillin & $\leq 0.25-1$ & 0.5 & 1 & 100 \\
\hline & gentamicin & $\leq 0.25-0.5$ & 0.5 & 0.5 & 100 \\
\hline & daptomycin & $0.12-1$ & 0.25 & 1 & 100 \\
\hline \multirow[t]{11}{*}{ S. epidermidis (7) } & ciprofloxacin & $\leq 0.12$ & & & 100 \\
\hline & cotrimoxazole & $\leq 2 / 38-4$ & & & 85.7 \\
\hline & clindamycin & $\leq 0.25$ & & & 100 \\
\hline & erythromycin & $\leq 0.25-\geq 8$ & & & 28.6 \\
\hline & tetracycline & $\leq 1$ & & & 100 \\
\hline & rifampicin & $\leq 0.5$ & & & 100 \\
\hline & linezolid & 1 & & & 100 \\
\hline & vancomycin & 1 & & & 100 \\
\hline & oxacillin & $\leq 0.25-4$ & & & 71.4 \\
\hline & gentamicin & $\leq 0.25->16$ & & & 71.4 \\
\hline & daptomycin & $0.25-0.5$ & & & 100 \\
\hline
\end{tabular}

*Two strains showed inducible clindamycin resistance. 
The oxacillin susceptibility results were confirmed by cefoxitin disk test and $m e c A$ PCR.

\section{Biofilm assays}

All $S$. aureus isolates, and only one out of seven $S$. epidermidis isolates were classified as slime producers by the Congo Red Agar (CRA) plate method, developing brown-black (S. aureus) or black (S. epidermidis) colonies.

All isolates were classified as biofilm-producing strains by the polystyrene microtiter plates (MtP) method.

When grown in brain heart infusion (BHI) supplemented with $1 \%$ glucose, biofilm development was significantly induced in twelve $S$. aureus and $\operatorname{six} S$. epidermidis strains while $4 \% \mathrm{NaCl}$ activated biofilm development in five $S$. aureus and one $S$. epidermidis strain (Figure 1). For these six strains $\mathrm{NaCl}$ was a stronger biofilm inducer than glucose.

Addition of DNase I did not affect bacterial biofilm stability. Although not statistically significant the lowest percentages of reduction of primary attachment $(<10 \%)$ were observed for those strains producing $\mathrm{NaCl}$ inducible biofilms (Figures 2 and 3).

All $\mathrm{NaCl}$-induced biofilms were susceptibile to sodium metaperiodate ( $>70 \%$ reduction in optical density (OD)) and resistant to proteinase $K$ (Figure 4 ). All the remaining biofilms (significantly or only slightly glucoseinduced) were resistant to sodium metaperiodate and substantially dispersed by treatment with proteinase K ( $>60 \%$ reduction in OD), with the exception of those produced by two $S$. aureus strains (both proteinase $\mathrm{K}$ and sodium metaperiodate resistant).

The different behaviours observed suggested different chemical compositions in the biofilm extracellular matrices.

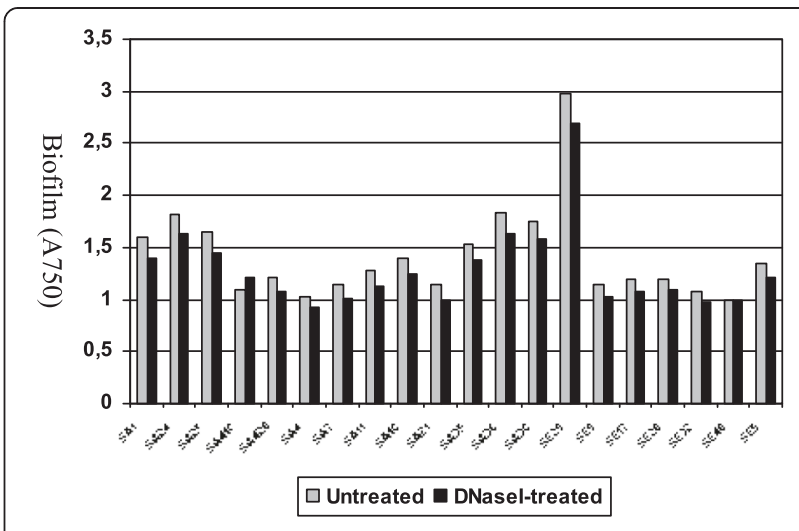

Figure 2 Susceptibility of S. aureus and S. epidermidis biofilms to treatment with DNase I. Strains SA 1, SA 24, SA 25, SA 418, SA 420 and SE 29 were grown in BHI supplemented with $4 \% \mathrm{NaCl}$ at $37^{\circ} \mathrm{C}$ for $24 \mathrm{~h}$ prior to treatment. The remaining strains were grown in $\mathrm{BH}$ supplemented with $1 \%$ glucose at $37^{\circ} \mathrm{C}$ for $24 \mathrm{~h}$ prior to treatment.

\section{Detection of MSCRAMM and biofilm genes}

All S. aureus harboured the icaA/D, atlA, clfA, FnA, eno and cna genes and the great majority carried sasG (10/ 13), ebpS (10/13) and fib (9/13), while only two strains carried $F n B$ (Table 2). No strain harboured the bap and bbp genes.

Two S. epidermidis carried ica genes. One S. epidermidis (classified as a slime producer according to the CRA plate method) carried both the icaA and icaD genes and another strain (classified as a non slime producer, by CRA plate method) was icaD positive.

All S. epidermidis harboured the atlE, aae, embp genes, the aap and the fbe genes were carried by six strains,
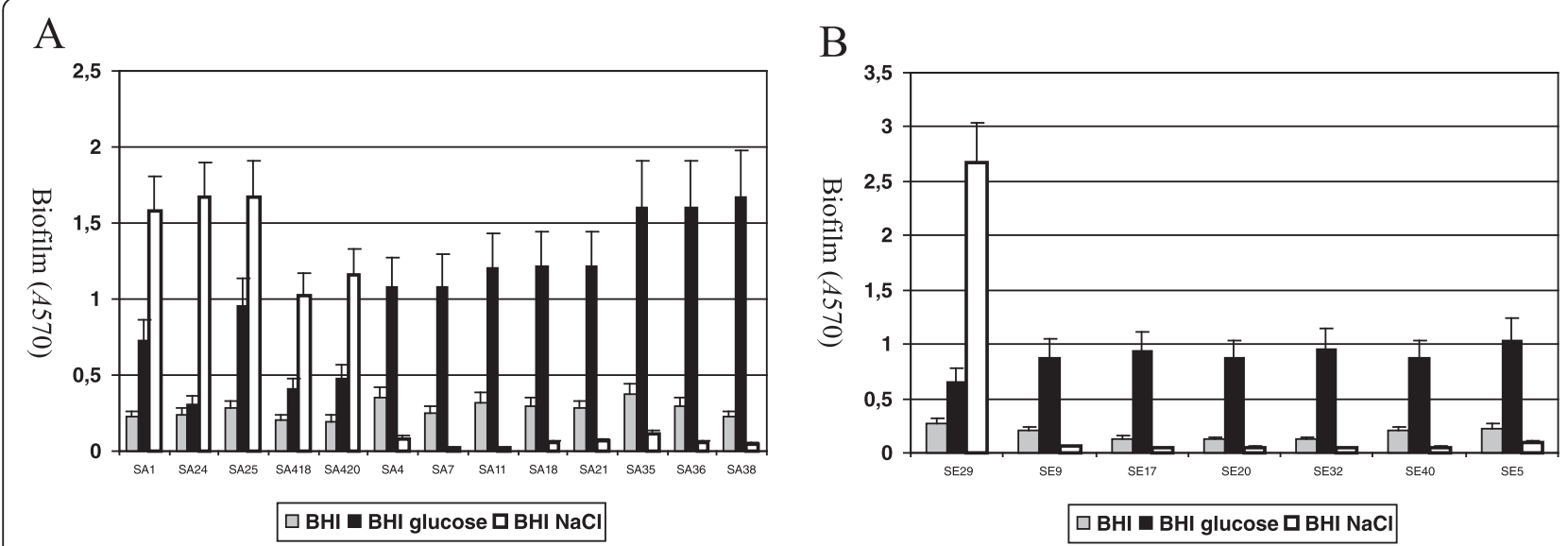

Figure 1 Biofilm formation in 13 S. aureus (A) and 7 S. epidermidis (B) strains studied. The strains were grown in $\mathrm{BH}$ medium or in BHI supplemented with $1 \%$ glucose or $4 \% \mathrm{NaCl}$ at $37^{\circ} \mathrm{C}$ for $24 \mathrm{~h}$. Biofilm formation in tissue culture-treated 96 -well plates was measured three times, and standard deviations, which were less than 20\%, are indicated. 


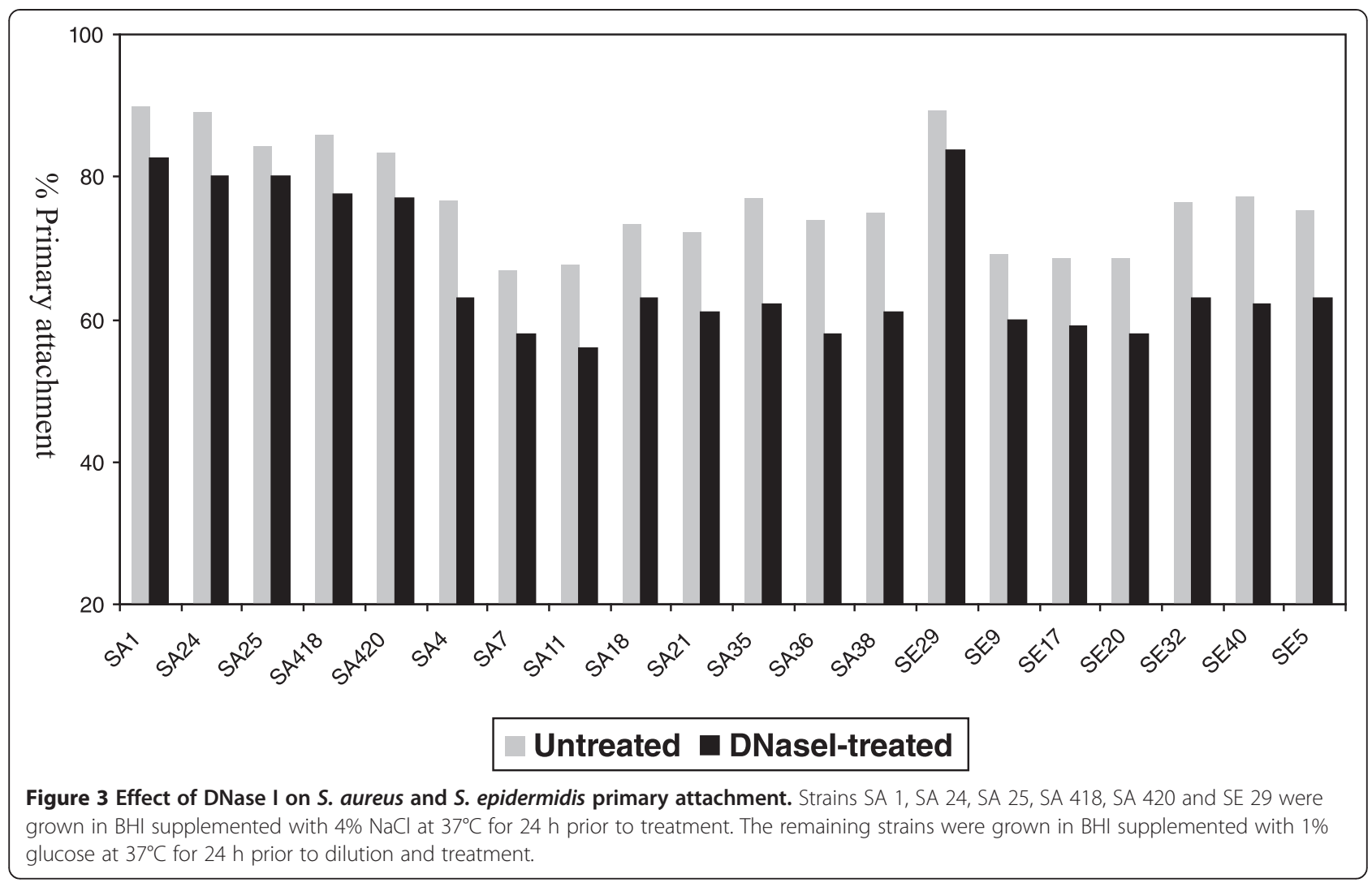

while four strains carried the $S d r F$ gene (Table 2). No strains harboured the bhp gene (Additional files 1 and 2).

\section{Expression of MSCRAMM and biofilm genes}

Under the experimental conditions used all strains expressed icaA/D genes with the exception of one S. epidermidis strain which did not express the icaD gene (Additional file 3).
For all S. aureus strains the RT-PCR amplicons showed positive expression signals for all the remaining genes tested with the exception of fib. All S. epidermidis strains expressed the atlE, aae, embp genes, and six strains out of seven expressed the $f b e$, aap genes.

Detection of S. aureus capsular and leukotoxin genes

Six strains were PCR-positive for capsular type 8 and seven for capsular type 5 genes (Additional file 1).

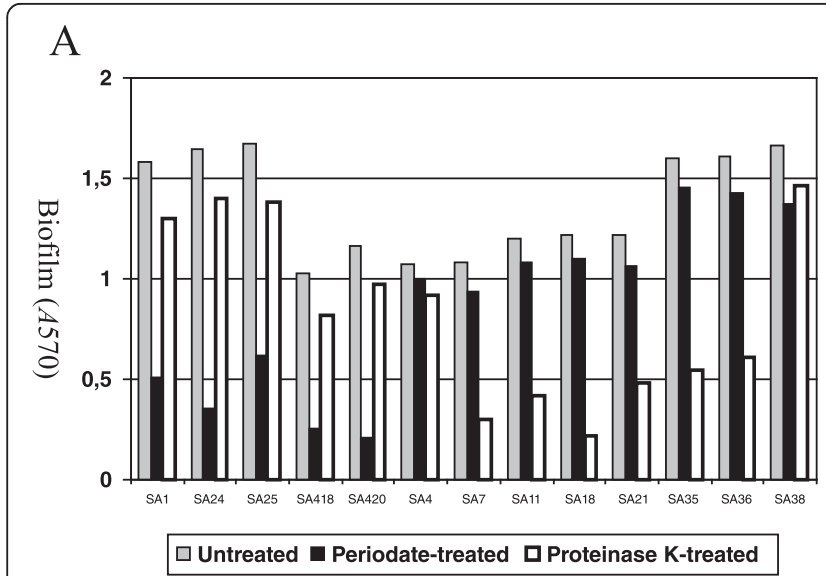

B

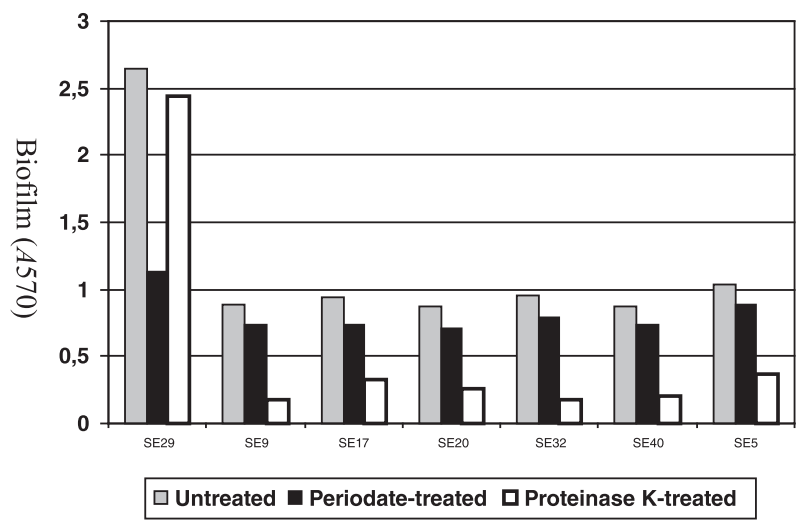

Figure 4 Susceptibility of S. aureus (A) and S. epidermidis (B) biofilms to treatment with sodium metaperiodate and proteinase K. Strains SA 1, SA 24, SA 25, SA 418, SA 420 and SE 29 were grown in $\mathrm{BH}$ supplemented with $4 \% \mathrm{NaCl}$ at $37^{\circ} \mathrm{C}$ for $24 \mathrm{~h}$ prior to treatment. The remaining strains were grown in $\mathrm{BH}$ supplemented with $1 \%$ glucose at $37^{\circ} \mathrm{C}$ for $24 \mathrm{~h}$ prior to treatment. 
Table 2 Distribution of MSCRAMM and biofilm genes among S. aureus and S. epidermidis

\begin{tabular}{|c|c|c|c|c|c|c|c|c|c|c|c|c|c|c|c|c|c|c|}
\hline & ebpS & eno & $A t \mid A / E$ & aae & aap & bap/bhp & sas $G$ & cna & $b b p$ & $f n b A$ & $f n b B$ & clfA & clfB & fbe & $s d r F$ & $e m b p$ & $f i b$ & $i c a A / D$ \\
\hline S. aureus (13) & 10 & 13 & 13 & n. t. & n.t. & 0 & 10 & 13 & 0 & 13 & 2 & 13 & 8 & n.t & n.t & n.t & 9 & 13 \\
\hline S. epidermidis (7) & n.t. & n.t. & 7 & 7 & 6 & 0 & n.t. & n.t. & n.t. & 0 & 0 & n.t. & n.t. & 6 & 4 & 7 & n.t. & $2^{*}$ \\
\hline
\end{tabular}

${ }^{*} 1$ strain was icaA negative and icaD positive.

Seven out of thirteen $S$. aureus strains carried the LukE/LukD leukotoxin genes, while the PVL and LukM leukotoxins genes were not detected.

\section{Randomly amplified polymorphic DNA (RAPD) polymerase chain reaction (PCR) profiles}

To rule out the possibility of infections due to one epidemic S. aureus or S. epidermidis strain, all isolates (13 S. aureus and 7 S. epidermidis) underwent RAPD PCR with three and two different primers respectively. All $S$. aureus and all S. epidermidis had different RAPD profiles (Additional files 4 and 5).

\section{S. aureus MLST and eBURST analysis}

As shown in Table 3, a total of 8 sequence types (STs) were revealed, which were further grouped into 6 clonal complexes (CCs).

\section{S. aureus agr typing}

The distribution of agr alleles among the $13 \mathrm{~S}$. aureus strains is provided in Table 3.

The agr type I was predominant (7/13; 53,8\%), followed by agr type II $(5 / 13 ; 38,5 \%)$. Only one $S$. aureus belonged to agr type III.

Table 3 Clonal relatedness of $13 \mathrm{~S}$. aureus isolates and their agr groups

\begin{tabular}{llll}
\hline Strains & agr group & Sequence type & Clonal complex \\
\hline SA1 & | & 45 & 45 \\
SA4 & III & 30 & 30 \\
SA7 & I & 45 & 45 \\
SA 11 & $\|$ & 15 & 5 \\
SA18 & $\|$ & 1162 & 10 \\
SA21 & I & 20 & 20 \\
SA24 & $\|$ & 5 & 5 \\
SA 25 & I & 22 & 22 \\
SA35 & $\|$ & 194 & 5 \\
SA 36 & $\|$ & 5 & 5 \\
SA 38 & I & 45 & 45 \\
SA 418 & I & 22 & 22 \\
SA 420 & | & 22 & 22 \\
\hline
\end{tabular}

${ }^{*} \mathrm{CC}$ s as defined by eBurst analysis with a stringent group definition with six of seven loci.

\section{Discussion}

Staphylococcal infection represents a major concern when associated with breast reconstruction, as it may necessitate additional hospitalization, antibiotic treatment, and in more serious cases removal of the device making subsequent reinsertion and re-expansion more difficult [5].

Theoretically, both endogenous and hospital-acquired staphylococci may gain access to breast implants during or following placement. Our data (susceptible antibiotypes, heterogeneity of the STs and the RAPD profiles) supports a community origin of the infecting microorganisms, in most cases. After accession to surgical implants, the essential factor in the evolution and persistence of infections is the formation of bacterial biofilm around implanted devices [11]. All isolates studied were able to form biofilm on polystyrene surfaces but, in contrast to $S$. aureus, the great majority of S. epidermidis isolates did not carry the ica $\mathrm{A}$ or ica $\mathrm{D}$ genes. Our results are in agreement with previous studies showing that the ica-operon is present and expressed in almost all $S$. aureus isolates, although the absence of icaoperon activity does not necessarily impact on the ability of $S$. epidermidis to cause clinical biofilm disease. In this study, only one out of seven $S$. epidermidis strains carried both icaA and icaD. In a recent letter, Persichetti and colleagues [12], described $10 \mathrm{~S}$. epidermidis causing periprosthetic breast infections and capsular contracture, yet they reported only three icaA and icaD positive strains. Although the number of cases analysed in both studies is limited, it seems that ica-independent biofilm formation plays a major role compared to ica-dependent mechanisms in S. epidermidis breast peri-implant infections. In contrast, all S. epidermidis studied carried and expressed the gene for Aap protein, a protein that has been shown to mediate biofilm formation in strains lacking the ica genes. Biofilm induction by glucose or $\mathrm{NaCl}$ (a known activator of ica operon transcription) had different effects on our strains and revealed that our strains had different mechanisms of biofilm development, irrespective of ica operon carriage. Proteinase K and sodium metaperiodate treatment confirmed that strains causing breast peri-implant infection can produce different types of biofilm extracellular matrix (involving polysaccharides, or proteins or both). Although not statistically significant DNase I appeared less effective in reducing bacterial attachment in those strains producing $\mathrm{NaCl}-$ induced biofilm, suggesting a minor role of extracellular 
DNA in these isolates. Our data adds further evidence that, in the context of peri-implant infections, biofilm formation is a complex, phenomenon involving distinct molecules, whose relative importance may vary depending on the different clinical settings. Addition of DNase I did not affect bacterial biofilm stability as already reported [13].

Genes coding for biofilm-associated molecules have been thoroughly studied [14] in S. aureus and S. epidermidis isolated from prosthetic joint infections (PJI).

The most striking difference observed between $S$. aureus strains isolated from PJI and breast implant infections was the rate of surface adhesin (sasG) and collagen adhesin (cna) genes found. The isolation of a cnapositive $S$. aureus strain was more probable in isolates from breast implant infections than from PJI (100\% vs $22-29 \%$ indicating that cna is of major importance in the specific context of breast implant infections. Other Authors [15-17] have shown the prevalence of the cna gene to be much higher in methicillin-resistant $S$. aureus (MRSA) (93\%) than methicillin-sensible S. aureus (MSSA) clones (46.6\%) and that cna positive strains appeared to be associated with capsular type 8 . However, our strains were all methicillin sensible (MS) and 7 out of 13 strains carried the cps 5 gene for capsular type 5 and the remaining cps8, suggesting that the site of infection may have been the driving force in selecting a subpopulation of cna positive $S$. aureus strains irrespective of other characteristics such as methicillin resistance and capsular type.

An elevated breast collagen concentration has been shown to be one of the greatest risk factors for developing breast carcinoma [18].

Breast implants, especially in oncologic patients, due to the increased collagen deposition, could be easily covered by a more dense collagen matrix and thus become more prone to adhesion of $S$. aureus strains able to bind collagen.

In contrast to $S$. aureus causing PJI, the great majority of our strains carried and expressed the sas $G$ gene (a gene coding for a surface protein that has been shown to promote biofilm formation and adherence to nasal epithelial cells).

This difference in distribution according to the site of infection, is remarkable as its $S$. epidermidis homologue aap (accumulation-associated protein) appears to be almost ubiquitously present. Further studies are needed to better characterize this protein, its function/s and to understand its role in different types of infections.

The gene coding for Bap, a cell wall protein found in bovine mastitis $S$. aureus isolates, involved in intercellular adhesion and biofilm formation was absent in all $S$. aureus isolates studied. Our results support the suggestion of other authors, that the role of Bap in human infections is doubtful [14].

Besides the ability to form biofilms, other authors have investigated the incidence of genes coding for leukocidal toxins in S. aureus isolated from implant orthopaedic infections. Panton-Valentine, LukE/LukD and LukM leukocidins are known to be associated with necrotic skin and soft tissue infections and could promote damage to peri-implant tissues. $l u k E / l u k D$ was the only gene found in strains from breast implant infections (53.8\%). Leukotoxin genes displayed a similar prevalence in strains from breast implants and PJIs, suggesting that LukE/ LukD could be the only relevant leukocidin in both types of implant-related infections.

The great majority of $S$. epidermidis analysed carried AtlE, aap, aae, embp and fbe genes, a condition already described for $S$. epidermidis isolated from catheterrelated bloodstream infections and PJIs as well as for commensal S. epidermidis, indicating that these proteins are valuable during both infection and colonization.

In contrast to $S$. aureus only three $S$. epidermidis strains carried a gene $(S d r F)$ coding for a surface protein binding collagen. This is not surprising, since adhesins that recognize host proteins coating the device seem to be the primary mechanism of adhesion in S. aureus, while $S$. epidermidis initial adherence is probably multifactorial [19].

Breast reconstruction has become a standard of care for almost all women requiring mastectomy for breast cancer. Reduction of mutilation greatly improves the psychological status of women without interfering with oncological treatment, However, the reconstructive approach may be compromised by early or late implant infection in $8 \%$ of patients in prospective series [20]. Further studies are needed to confirm our observation and to verify if patients colonized by cna positive strains are at higher risk of breast peri-implant infections than those colonized by cna negative $S$. aureus. If this holds true, screening of patients before and after reconstructive surgery at regular intervals could be extremely useful to identify those colonized and thus concentrate management, and resources. Should colonization with cnapositive strains confirm to be predictive for higher risk of implant infection, effective prophylactic strategies/ treatments could be devised to reduce the risk of infection of reconstruction breast implants.

\section{Conclusions}

S. aureus and S. epidermidis breast peri-implant infections are caused by heterogeneous strains with different biofilm development mechanisms. Since the collagen adhesin (cna) gene is not ubiquitously distributed among $S$. aureus, this protein could have an important role in the cause of breast peri-implant infections. Further 
studies are needed to confirm our observation and eventually recommend screening of patients before and after reconstructive surgery to identify those colonized by cna-positive $S$. aureus and at higher risk of peri-implant infections.

\section{Methods}

Twenty staphylococci (13 S. aureus isolates and 7 S. epidermidis isolates) were studied.

The isolates represented non repetitive strains causing periprosthetic infection in patients who underwent breast implantation (silicone mammary prosthesis) after mastectomy for breast cancer at the Oncology Institute (IST) of Genoa, Italy, between January 2011 and January 2013.

Clinical data and isolates were taken as part of standard patient care and according to this condition the study was exempt from specific ethics commitee scrutiny and approval. Informed consent for the use of clinical data has been obtained by patients.

Infection was defined as a complication occurring after breast implant surgery that was characterized by three or more of the following findings: pain, local swelling, erythema, pus, fever, seroma, wound dehiescence, or perforation of the skin, as previously described [20].

All isolates were identified using a commercial biochemical tests (API Staph identification strip; bioMérieux, Marcy-l'Etoile, France).

Strains were isolated from implants (8), peri-implant fluids (6), capsular tissues (4), a tissue expander (1) and a pus sample (1).

A sonication procedure was adopted to detach adherent bacteria from the expander, implants and capsular tissues [21].

\section{Susceptibility tests}

The minimal inhibitory concentrations (MICs) of oxacillin, ciprofloxacin, gentamicin, erythromycin, clindamycin, co-trimoxazole, tetracycline, rifampin, vancomycin and linezolid were determined by the broth microdilution method following the European committee for Antimicrobial Susceptibility testing (EUCAST) (Version 4.0, 2014) guidelines and interpretative criteria [22,23]. Daptomycin-MICs were determined by E-test (bioMérieux, Marcy-l'Etoile, France) on Muller-Hinton agar (Biolife, Milan, Italy) supplemented with $50 \mathrm{mg} / \mathrm{L}$ calcium. S. aureus ATCC-29213 was included for quality control of antimicrobial susceptibility patterns. Cefoxitin disk diffusion test was used to confirm oxacillin resistance (EUCAST, version 4.0, 2014) [23].

Inducible clindamycin resistance was evaluated using the D-zone test as recommended by EUCAST (Version $4.0,2014)$ [23].

\section{Detection of S. epidermidis mecA gene}

The presence of the $\boldsymbol{m e c} \boldsymbol{A}$ gene in S. epidermidis strains was investigated by PCR using primers and conditions described by Vannuffel et al. [24].

\section{Characterization of slime-producing ability}

The phenotypic characterization of slime-producing ability by culture of the strains on CRA plates, prepared by adding $0.8 \mathrm{~g}$ of Congo red (Sigma, Missouri) and $36 \mathrm{~g}$ of saccharose (Sigma, Missouri) to $1 \mathrm{~L}$ of brain heart infusion agar (Oxoid, Basingstoke, Hampshire, England) as described by Freeman et al. [25]. S. aureus colonies on CRA were kept under observation for up to $72 \mathrm{~h}$, as described by Arciola et al. [26].

\section{Biofilm assays}

The presence and extent of biofilm structures, produced by staphylococci was quantified spectrophotometrically at $570 \mathrm{~nm}$ using MtP plates following the indications described by Christensen et al., [27] and as reported previously by this group [28]. In accordance with the original method, strains with OD values $<0.120$ were considered as negative, those with ODs $>0.120$ and $<0.240$ were regarded as weak biofilm-producers. An OD value $>$ 0.240 was indicative of biofilm-producing bacterial strains. For each isolate the MtP test was repeated in triplicate.

In order to assess glucose- and $\mathrm{NaCl}$-induced biofilm formation, bacteria were grown in 96-well polystyrene microtitre plates in BHI medium or BHI supplemented with $1 \%$ glucose or $4 \% \mathrm{NaCl}$ at $37^{\circ} \mathrm{C}$ for $24 \mathrm{~h}$. Biofilms were quantified spectrophotometrically as described by O'Neill et al. [29].

Biofilm stability against proteinase K, sodium metaperiodate and DNaseI treatment was tested for both species as described previously [29]. Effect of DNaseI on biofilm development was assessed as described by Houston et al. [30].

Two-tailed, two sample equal variance Student's t-tests (Microsoft Excel 2007) were used to determine statistically significant differences in biofilm-forming capacity and biofilm stability.

\section{PCR-method for the detection of MSCRAMM and biofilm genes}

The presence of ica $\mathrm{A}$ and ica $\mathrm{D}$ genes was detected by PCR using primers and conditions described by O'Neill et al., Rohde et al., Arciola et al. and de Silva et al. $[26,29,31,32]$.

The genes encoding the autolysins/adhesins responsible for primary attachment to abiotic surfaces (atlA/ atlE and $a a e$ ), the components causing intercellular aggregation (bap, sas G, bhp, aap) and microbial surface components recognizing adhesive matrix molecules 
(MSCRAMMs) bbp, cna, fib, fnbA, fnbB, clfA, clfB, fbe, ebpS, eno, $s d r F$ and embp, were amplified by PCR using the primers and conditions summarized in (Additional file 6: Table S3) [33-45].

\section{Expression of MSCRAMM and biofilm genes}

Expression of MSCRAMM and biofilm genes was assessed by Reverse transcription (RT)-PCR for all staphylococcal strains.

RNA was purified from cultures grown at $37^{\circ} \mathrm{C}$ in $\mathrm{BHI}$ medium supplemented with $1 \%$ glucose (strains producing glucose-induced biofilms) or $4 \% \mathrm{NaCl}$ (strains producing $\mathrm{NaCl}$-induced biofilms) to an $\mathrm{A}_{600}$ of 2.0. Total bacterial RNA was isolated using the High Pure RNA Isolation Kit (Roche, Mannheim, Germany) according to the manufacturer's instructions. After purification, contaminating DNA was removed with DNase I recombinant RNase-free (10 U/40 $\mu \mathrm{g}$ of total bacterial RNA) at $37^{\circ} \mathrm{C}$ for $20 \mathrm{~min}$. The RNA was then repurified using RNeasy Mini columns (Qiagen, Inc.). The amount of RNA recovered was determined spectrophotometrically, and the absence of DNA was verified by PCR using primers described in the Multilocus sequence typing (MLST) database (http://www.mlst.net) corresponding to the constitutively expressed phosphate acetyltransferase gene $(p t a)$ for $S$. aureus and the carbamate kinase gene $(\operatorname{arc} C)$ for $S$. epidermidis. Samples were then stored at $-80^{\circ} \mathrm{C}$.

RT-PCR was performed using the Transcriptor First Strand cDNA synthesis kit (Roche, Mannheim, Germany) and the cDNA was directly used as a template to amplify selected MSCRAMM and biofilm genes using the same primers and PCR conditions mentioned earlier (Additional file 6: Table S3). PCR products were separated by electrophoresis in a $1.2 \%$ agarose gel and visualized with ethidium bromide under UV light.

\section{Detection of S. aureus capsular and leukotoxin genes}

PCR amplification of S. aureus cap5 (to assess for genes encoding capsular type 5), and cap8 (to assess for genes encoding capsular type 8), was performed using primers and conditions described by Sau et al., [46].

Detection of the Panton-Valentine leukocidin (PVL) and LukE/LukD and LukM leukotoxin genes was performed for all $S$. aureus isolates by PCR as previously reported [47,48] (Additional file 6: Table S3).

\section{RAPD}

RAPD analysis was performed on $S$. aureus strains using three separate primers, AP-PCR1 (5' -ggTTgggTgA gAATTgcAcg) AP-PCR7 (5' -gTggATgcgA) and AP-PCR ERIC-2 (5'-AAgTAAgTgAcTGGGGTgAgCg), with PCR conditions described by Van Belkum et al. [49].
For S. epidermidis strains RAPD analysis was performed using primers AP-PCR ERIC-2 and AP-PCR7.

The RAPD patterns were considered to be different when the profiles differed by at least one band.

\section{S. aureus MLST and eBURST analysis}

MLST was performed for all S. aureus isolates according to the protocol described on the S. aureus MLST website (http://saureus.mlst.net). The allele types and the resulting sequence types were determined by submitting the allelic profile of representative alleles to the $S$. aureus MLST database via the Internet. Sequence types were clustered into groups by eBURST analysis (v3.0 software) with a stringent group definition with six of seven loci to determine the clonal relationship of the isolates.

\section{S. aureus agr typing}

For all $S$. aureus the agr locus was typed by a multiplex PCR as previously described [50].

\section{Additional files}

\section{Additional file 1: Table S1. Genetic and phenotypic characteristics of 13 S. aureus strains studied. \\ Additional file 2: Table S2. Genetic and phenotypic characteristics of 7S. epidermidis strains studied.}

Additional file 3: Figure S1. Comparison of ica operon expression in S. aureus and $\mathrm{S}$. epidermidis grown in $\mathrm{BHI}$ medium or in $\mathrm{BH}$ supplemented with $4 \% \mathrm{NaCl}$ or $1 \%$ glucose (Glu).

Additional file 4: Figure S2. RAPD fingerprinting of the $13 \mathrm{~S}$. aureus strains studied. RAPD profiles generated by primer AP-PCR1 (A), primer AP-PCR7 (B) and primer AP-PCR ERIC-2 (C). The DNA molecular weight marker XIV (Roche, Mannheim, Germany) is in lanes 1 and 15.

Additional file 5: Figure S3. RAPD fingerprinting of the $7 \mathrm{~S}$. epidermidis strains studied. RAPD profiles generated by primer AP-PCR7 (A) and primer AP-PCR ERIC-2 (B). The DNA molecular weight marker XIV (Roche, Mannheim, Germany) is in lanes 1 and 9.

Additional file 6: Table S3. Primers used for PCR-based detection of staphylococcal factors involved in the pathogenesis of foreign-body associated infections.

\section{Abbreviations}

MSCRAMMs: Microbial surface components recognizing adhesive matrix molecules; (PIA): Extracellular polysaccharide promoting intercellular adhesion; PNAG: Polymeric N-acetyl-glucosamine; CRA: Congo red agar; MtP: Polystyrene microtiter plates; BHI: Brain heart infusion; OD: Optical density; RAPD: Randomly amplified polymorphic DNA; PCR: Polymerase chain reaction; PJl: Prosthetic joint infections; MRSA: Methicillin-resistant S. aureus; MSSA: Methicillin-susceptible S. aureus; MS: Methicillin-sensible; aap: Accumulation-associated protein; MIC: Minimum inhibitory concentration; EUCAST: European committee for antimicrobial susceptibility testing; RT: Reverse transcription; MLST: Multi locus sequencing typing; PVL: Panton-Valentine leukocidin; CC: Clonal complex.

\section{Competing interests}

The authors declare that they have no competing interests.

\section{Authors' contributions}

RB carry out the experiments, PM, FS and BI contributed to collect clinical samples and data and revised the manuscript, ADM designed the study and revised the manuscript, AM designed the study, carry out the experiments 
and wrote the article. All authors read and approved the final version for publication.

\section{Authors' information}

Ramona Barbieri is a Microbiology PhD student working at the Microbiology Unit, DISC, University of Genoa, Italy. Marianna Pesce, Simonetta Franchelli and Ilaria Baldelli work at the Reconstruction Plastic Surgery Unit, San Martino IST, Genoa and their main research topics are plastic surgery and breast cancer. Andrea De Maria, is Associate Professor in Infectious Diseases at the University of Genoa, Genoa, Italy. His research fields include: immunopathogenesis of chronic and persistent infections (HIV, HCV, HPV, HTLV and Mycobacteria) and control and therapy of infectious diseases in oncologic patients. Anna Marchese is Associate Professor of Clinical Microbiology at the University of Genoa, Genoa, Italy. Her research fields include: epidemiology of mechanisms of antibiotic resistance, antimicrobial susceptibility testing, antimicrobial profile of new drugs, bacterial genetics. She has published more than 80 international papers.

\section{Acknowledgements}

We would like to thank Jennifer McDermott (Genoa, Italy) for the English revision of the manuscript. The authors wish also to thank Dr. Michaela Adami and Dr. Maria Stella Leone for heir help in clinical samples collection. Preliminary results of this work were presented as a poster at the 23nd European Congress of Clinical Microbiology and Infectious Diseases (ECCMID), Berlin, 2013.

\section{Author details}

${ }^{1}$ Microbiology Unit DISC, University of Genoa, Genoa, Italy. ${ }^{2}$ IRCCS-AOU San Martino IST, Reconstruction Plastic Surgery Unit, DISC, University of Genoa, Genoa, Italy. ${ }^{3}$ IRCCS-AOU San Martino IST, Reconstruction Plastic Surgery Unit, Genoa, Italy. ${ }^{4}$ IRCCS-AOU San Martino IST, Infectious Diseases Unit, DISSAL, University of Genoa, Genoa, Italy. ${ }^{5}$ IRCCS-AOU San Martino IST, Microbiology Unit DISC, University of Genoa, Largo Rosanna Benzi 10, 16132 Genoa, Italy.

\section{Received: 12 August 2014 Accepted: 29 January 2015} Published online: 10 February 2015

\section{References}

1. Spiegel AJ, Butler CE. Recurrence following treatment of ductal carcinoma in situ with skin-sparing mastectomy and immediate breast reconstruction. Plast Reconstr Surg. 2003;111 Suppl 2:706-11.

2. Mustonen P, Lepistö J, Papp A, Berg M, Pietiläinen T, Kataja V, et al. The surgical and oncological safety of immediate breast reconstruction. Eur J Surg Oncol. 2004;30 Suppl 8:817-23.

3. Radovanovic Z, Radovanovic D, Golubovic A, Ivkovic-Kapicl T, Bokorov B, Mandic A. Early complications after nipple-sparing mastectomy and immediate breast reconstruction with silicone prosthesis: results of 214 procedures. Scand J Surg. 2010;99 Suppl 3:115-8.

4. Phillips BT, Bishawi M, Dagum AB, Khan SU, Bui DT. A systematic review of antibiotic use and infection in breast reconstruction: what is the evidence? Plast Reconstr Surg. 2013;131 Suppl 1:1-13.

5. Kendrick AS, Chase CW. Salvage of an infected breast tissue expander with an implant sizer and negative pressure wound management. Plast Reconstr Surg. 2008;121 Suppl 3:138e-9.

6. Otto M. Molecular basis of Staphylococcus epidermidis infections. Semin Immunopathol. 2012;34 Suppl 2:201-14.

7. Jabbouri S, Sadovskaya I. Characteristics of the biofilm matrix and its role as a possible target for the detection and eradication of Staphylococcus epidermidis associated with medical implant infections. FEMS Immunol Med Microbiol. 2010;59 Suppl 3:280-91.

8. Götz F. Staphylococcus and biofilms. Mol Microbiol. 2002;43(6):1367-78.

9. O'Gara JP. ica and beyond: biofilm mechanisms and regulation in Staphylococcus epidermidis and Staphylococcus aureus. FEMS Microbiol Lett. 2007;270 Suppl 2:179-88.

10. Fredheim EG, Klingenberg C, Rohde H, Frankenberger S, Gaustad P, Flaegstad T, et al. Biofilm formation by Staphylococcus haemolyticus. J Clin Microbiol. 2009;47(4):1172-80.

11. Darouiche RO. Treatment of infections associated with surgical implants. N Engl J Med. 2004;350 Suppl 14:1422-9.
12. Persichetti P, Giovanni Lombardo GA, Marangi GF, Gherardi G, Dicuonzo G. Capsular contracture and genetic profile of ica genes among Staphylococcus epidermidis isolates from subclinical periprosthetic infections. Plast Reconstr Surg. 2011;127 Suppl 4:1747-8.

13. Montanaro L, Poggi A, Visai L, Ravaioli S, Campoccia D, Speziale P, et al. Extracellular DNA biofilms. Int J Artif Organs. 2011;34:824-31.

14. Rohde H, Burandt EC, Siemssen N, Frommelt L, Burdelski C, Wurster S, et al. Polysaccharide intercellular adhesin or protein factors in biofilm accumulation of Staphylococcus epidermidis and Staphylococcus aureus isolated from prosthetic hip and knee joint infections. Biomaterials. 2007;28 Suppl 9:1711-20.

15. Atshan SS, Nor Shamsudin M, Sekawi Z, Lung LT, Hamat RA, Karunanidhi A Mateg Ali A, Ghaznavi-Rad E, Ghasemzadeh-Moghaddam H, Chong Seng JS, Nathan JJ, Pei CP: Prevalence of adhesion and regulation of biofilm-related genes in different clones of Staphylococcus aureus. J Biomed Biotechnol 2012; 2012:976972. http://dx.doi.org/10.1155/2012/976972.

16. Cassat JE, Dunman PM, McAleese F, Murphy E, Projan SJ, Smeltzer MS. Comparative genomics of Staphylococcus aureus musculoskeletal isolates. J Bacteriol. 2005;187 Suppl 2:576-92.

17. Ryding U, Flock Jl, Flock M, Söderquist B, Christensson B. Expression of collagen-binding protein and types 5 and 8 capsular polysaccharide in clinical isolates of Staphylococcus aureus. J Infect Dis. 1997;176 Suppl 4:1096-9.

18. McCormack VA, dos Santos Silva I. Breast density and parenchymal patterns as markers of breast cancer risk: a meta-analysis. Cancer Epidemiol Biomarkers Prev. 2005;15 Suppl 6:1159-69.

19. Fluckiger U, Ulrich M, Steinhuber A, Döring G, Mack D, Landmann R, et al. Biofilm formation, icaADBC transcription, and polysaccharide intercellular adhesin synthesis by staphylococci in a device-related infection model. Infect Immun. 2005;73 Suppl 3:1811-9.

20. Franchelli S, Vassallo F, Porzio C, Mannucci M, Priano V, Schenone E, et al. Breast implant infections after surgical reconstruction in patients with breast cancer: assessment of risk factors and pathogens over extended postoperative observation. Surg Infect (Larchmt). 2012;13 Suppl 3:154-8.

21. Rieger UM, Pierer G, Lüscher NJ, Trampuz A. Sonication of removed breast implants for improved detection of subclinical infection. Aesthetic Plast Surg. 2009;33 Suppl 3:404-8.

22. European Committee on Antimicrobial Susceptibility Testing (EUCAST) (2014) MIC determination of non-fastidious and fastidious organisms, version 4.0. http://www.eucast.org/ast_of_bacteria/mic_determination.

23. European Committee on Antimicrobial Susceptibility Testing (EUCAST) (2014) Breakpoint tables for interpretation of MICs and zone diameters, version 4.0. http://www.eucast.org/clinical_breakpoints/.

24. Vannuffel P, Gigi J, Ezzedine H, Vandercam B, Delmee M, Wauters G, et al. Specific detection of methicillin-resistant Staphylococcus species by multiplex PCR. J Clin Microbiol. 1995;33 Suppl 11:2864-7.

25. Freeman DJ, Falkiner FR, Keane $C T$. New method for detecting slime production by coagulase-negative staphylococci. J Clin Pathol. 1989;42:872-4.

26. Arciola CR, Baldassarri L, Montanaro L. Presence of icaA and icaD genes and slime production in a collection of staphylococcal strains from catheterassociated infections. J Clin Microbiol. 2001;39 Suppl 6:2151-6.

27. Christensen GD, Simpson WA, Younger JJ, Baddour LM, Barrett FF, Melton $\mathrm{DM}$, et al. Adherence of coagulase-negative staphylococci to plastic tissue culture plates: a quantitative model for the adherence of staphylococci to medical devices. J Clin Microbiol. 1985;22:996-1006.

28. Roveta S, Marchese A, Schito GC. Activity of daptomycin on biofilms produced on a plastic support by Staphylococcus spp. Int J Antimicrob Agents. 2008:31 Suppl 4:321-8.

29. O'Neill E, Pozzi C, Houston P, Smyth D, Humphreys H, Robinson DA, et al. Association between methicillin susceptibility and biofilm regulation in Staphylococcus aureus isolates from device-related infections. J Clin Microbiol. 2007:45 Suppl 5:1379-88.

30. Houston P, Rowe SE, Pozzi C, Waters EM, O'Gara JP. Essential role for the major autolysin in the fibronectin-binding protein mediated Staphylococcus aureus biofilm phenotype. Infect Immun. 2011;79:1153-65.

31. Rohde H, Knobloch JK, Horstkotte MA, Mack D. Correlation of Staphylococcus aureus icaADBC genotype and biofilm expression phenotype. J Clin Microbiol. 2001;39 Suppl 12:4595-6.

32. de Silva GD, Kantzanou M, Justice A, Massey RC, Wilkinson AR, Day NP, et al. The ica operon and biofilm production in coagulase-negative Staphylococci associated with carriage and disease in a neonatal intensive care unit. J Clin Microbiol. 2002;40:382-8. 
33. Wootton M, Bennett PM, MacGowan AP, Walsh TR. Reduced expression of the at/ autolysin gene and susceptibility to autolysis in clinical heterogeneous glycopeptide-intermediate Staphylococcus aureus(hGISA) and GISA strains. J Antimicrob Chemother. 2005;56:944-7.

34. Vandecasteele SJ, Peetermans WE, Merckx R, Van Eldere J. Expression of biofilm-associated genes in Staphylococcus epidermidis during in vitro and in vivo foreign body infections. J Infect Dis. 2003;188 Suppl 5:730-7.

35. Lou Q, Zhu T, Hu J, Ben H, Yang J, Yu F, et al. Role of the SaeRS twocomponent regulatory system in Staphylococcus epidermidis autolysis and biofilm formation. BMC Microbiol. 2011;11:146. http://dx.doi.org/10.1186/ 1471-2180-11-146.

36. Tormo MA, Knecht E, Götz F, Lasa I, Penadés JR. Bap-dependent biofilm formation by pathogenic species of Staphylococcus: evidence of horizontal gene transfer? Microbiology. 2005;151(Pt 7):2465-75.

37. Abraham NM, Jefferson KK. A low molecular weight component of serum inhibits biofilm formation inStaphylococcus aureus. Microb Pathog. 2010;49 Suppl 6:388-91.

38. Gu J, Li H, Li M, Vuong C, Otto M, Wen Y, et al. Bacterial insertion sequence IS256 as a potential molecular marker to discriminate invasive strains from commensal strains of Staphylococcus epidermidis. J Hosp Infect. 2005:61 Suppl 4:342-8.

39. Monk AB, Archer GL. Use of outer surface protein repeat regions for improved genotyping of Staphylococcus epidermidis. J Clin Microbiol. 2007:45 Suppl 3:730-5

40. Tristan A, Ying L, Bes M, Etienne J, Vandenesch F, Lina G. Use of multiplex PCR to identify Staphylococcus aureus adhesins involved in human hematogenous infections. J Clin Microbiol. 2003;41:4465-7.

41. Montanaro L, Arciola CR, Baldassarri L, Borsetti E. Presence and expression of collagen adhesin gene (cna) and slime production in Staphylococcus aureus strains from orthopaedic prosthesis infections. Biomaterials. 1999:20:1945-9.

42. Vancraeynest D, Hermans K, Haesebrouck F. Genotypic and phenotypic screening of high and low virulence Staphylococcus aureus isolates from rabbits for biofilm formation and MSCRAMMs. Vet Microbiol. 2004;103(Suppl 3-4):241-7.

43. Ugolotti E, Bandettini R, Marchese A, Gualco L, Vanni I, Borzi L, et al. Molecular characterization of hospital-acquired methicillin-resistant Staphylococcus aureus strains in pediatric outbreaks using variable tandem repeat analysis with spa and ClfB typing. Diagn Microbiol Infect Dis. 2011;69 Suppl 2:213-7.

44. de Araujo GL, Coelho LR, de Carvalho CB, Maciel RM, Coronado AZ, Rozenbaum $\mathrm{R}$, et al. Commensal isolates of methicillin-resistant Staphylococcus epidermidis are also well equipped to produce biofilm on polystyrene surfaces. J Antimicrob Chemother. 2006;57:855-64.

45. Nilsson M, Frykberg L, Flock Jl, Pei L, Lindberg M, Guss B. A fibrinogen-binding protein of Staphylococcus epidermidis. Infect Immun. 1998:66:2666-73.

46. Sau S, Bhasin N, Wann ER, Lee JC, Foster TJ, Lee CY. The Staphylococcus aureus allelic genetic loci for serotype 5 and 8 capsule expression contain the type-specific genes flanked by common genes. Microbiology. 1997;143:2395-405

47. Lina G, Piémont Y, Godail-Gamot F, Bes M, Peter MO, Gauduchon V, et al. Involvement of Panton-Valentine leukocidin-producing Staphylococcus aureus in primary skin infections and pneumonia. Clin Infect Dis. 1999;29:1128-32

48. Jarraud S, Mougel C, Thioulouse J, Lina G, Meugnier H, Forey F, et al Relationships between Staphylococcus aureus genetic background, virulence factors, agr groups (alleles), and human disease. Infect Immun. 2002;70:631-41.

49. van Belkum A, Kluytmans J, van Leeuwen W, Bax R, Quint W, Peters E, et al, Multicenter evaluation of arbitrarily primed PCR for typing of Staphylococcus aureus strains. J Clin Microbiol. 1995;33:1537-47.

50. Lina G, Boutite F, Tristan A, Bes M, Etienne J, Vandenesch F. Bacterial competition for human nasal cavity colonization: role of Staphylococcal agr alleles. Appl Environ Microbiol. 2003;69:18-23.

\section{Submit your next manuscript to BioMed Central and take full advantage of:}

- Convenient online submission

- Thorough peer review

- No space constraints or color figure charges

- Immediate publication on acceptance

- Inclusion in PubMed, CAS, Scopus and Google Scholar

- Research which is freely available for redistribution

Submit your manuscript at www.biomedcentral.com/submit 